\title{
Nurse Managers' Attitude and Competency Towards Delegation in Jeddah City
}

\author{
Roaa Sabri Gassas*, Sabah Mahmoud Mahran, Hasnah Irfan Banjar \\ Public Health Nursing Department, King Abdulaziz University, Jeddah, Saudi Arabia \\ Email address: \\ roaa-sabri@hotmail.com (R. S. Gassas) \\ ${ }^{*}$ Corresponding author \\ To cite this article: \\ Roaa Sabri Gassas, Sabah Mahmoud Mahran, Hasnah Irfan Banjar. Nurse Managers' Attitude and Competency Towards Delegation in \\ Jeddah City. American Journal of Nursing Science. Vol. 6, No. 2, 2017, pp. 72-79. doi: 10.11648/j.ajns.20170602.11
}

Received: December 24, 2016; Accepted: January 7, 2017; Published: February 3, 2017

\begin{abstract}
Delegation is the key for nurse managers and future leaders in order to guarantee productive outcomes. The use of delegation in nursing management can solve many issues including nurse shortages. The study aimed to describe nurse managers' attitude and competency to delegate effectively in a hospital setting. Descriptive correlational design was used which is a type of non-experimental design to collect data from five hospitals, first is University Hospital affiliated to King Abdulaziz University, other four hospitals are affiliated to the Ministry of health. Non probability purposive sampling technique was used to recruit 90 nurse managers. Data were collected by a questionnaire to measure nurse mangers, attitude and competency in delegation. In general nurse managers were unsure about their attitude towards delegation, but agreed that it saves time. Regarding competency, nurse managers' agreed on the importance of competency and that communication is an important part of delegation. All nurse managers agreed that they were familiar with their legal responsibility regarding delegation. The study concluded that there is a highly significant correlation between the attitude and competency where Pearson correlation coefficient is $0.000^{* *}$. This study recommended that nurse managers should communicate and facilitate the delegation process through developing clear guidelines as well as creating an environment that supports delegation, resolution of conflict and encourages teamwork.
\end{abstract}

Keywords: Delegation, Nurse Managers, Attitude and Competency

\section{Introduction}

Delegation is a vital skill of nurse mangers. Professional nurse managers need to be knowledgeable and responsible in order to achieve effective delegation [9]. It is an important element in day-to-day nursing activities and one of the reasons why organisations must have clear policies and guidelines regarding delegation. Nurse managers are actively involved in delegation, as required by their duties [25]. One study carried out in Saudi Arabia found that lack of delegation is one of the most common stressors; leading to work stress and turnover [1]. Moreover, it is a great tool to reduce turnover among novice nurses, especially that $21 \%$ to $50 \%$ of new graduates are leaving the profession in the first or second year [6]. Using skills such as time management, prioritization, working in a non-threatening environment and creating real clinical scenarios can help nurse managers to practice and teach appropriate delegation [3].

Delegation can be defined as "the transferring of responsibility for the performance of an activity to another, with the formal retention of accountability for the outcome" [14]. There are many factors may affect delegation such as administration rules; skill mix; organisation structure; staffing; communication; sophisticated clinical judgment; critical thinking; decision making and lack of necessary regulation [26] \& [20].

\section{Significance of the Study}

Based on a study done to assess new nurse competencies they found that only $10 \%$ of participants were satisfied with the ability of newly registered nurses to delegate tasks. Amongst 36 competencies, the satisfaction with delegation was ranked the lowest [4]. Delegation is highly recommended tool for managers at all levels The idea of 
delegation is to have someone else who knows how to perform a task and is highly associated with unit productivity [19]. Furthermore, the current world wide nursing shortage makes delegation an important tool in the retention of nurses and reduction of stress. Additionally, the lack of international guidelines for effective delegation also makes it very difficult for nurses to provide safe nursing practice [24]. Due to limited previous studies about delegation, The researcher hoped that this study may provide the nursing profession with recommendations that will help in achieving successful delegation through describe the nurse managers' attitude and competency regarding delegation and their ability to delegate effectively in Saudi governmental hospitals.

\section{Research Question}

The following are the research questions addressed in this study:

What is the nurse managers' attitude towards delegation?

What is the nurse managers' competency to delegate?

What is the relationship between nurse manager attitude and competency towards delegation?

\section{Aim}

To describe nurse managers' attitude and competency to delegate effectively in a hospital setting through:

\section{Objectives}

1. Assessment of nurse managers' attitude towards delegation.

2. Identify nurse managers' competency to delegate.

3. Illustrate the relationship between nurse managers' attitude and competency regarding delegation.

\section{Methodology}

\subsection{Research Design}

This study is part of a master dissertation entitled "Nurse Managers' Attitude and Competency Towards Delegation in Jeddah City". The study's design is quantitative descriptive correlation, which is a type of non-experimental design. This design was chosen because it indicates the relationship between two variables and how they are related. The relationship between variables can be detected through statistical tests.

\subsection{Settings}

This study was conducted at five hospitals; King Abdulaziz University Hospital, The other four hospitals are King Fahd General Hospital; Almsaeidih Maternity and Children's; King Abdulaziz Hospital Al Mahjar and King Faisal Specialist Hospital and Research Center. The latter four hospitals are affiliated to the Ministry of Health

\subsection{Sampling}

The Purposive sampling technique was applied which is a type of nonpropabilty sampling. Total studied sample was 90 participants includes those working in the chosen hospitals as nurse mangers minimum of one year's experience.

\subsection{Data Collection Tools}

One questionnaire was used for collecting data. It is consisted of three parts. The first part was developed by the researcher to collect data related to demographic characteristics such as age, years of experience, level of education and so on. The second part consists of 11 questions, this questionnaire aimed to measure nurse managers' attitude. The questionnaire was adapted from Poteet (1984). The third part of the questionnaire consists of 16 questions aimed to measure nurse mangers competency, adapted from Tómasdóttir \& Geirsdóttir (1998).

\subsection{Reliability and Validity}

The Reliability and internal consistency was measured for this study. The result for nurse manger attitude was 0.900 and for competency 0.777 . A panel of nursing experts in nursing administration examined the validity of the tool. The tool was tested for clarity, vagueness and measurement of the desired goals. It was modified based on their recommendation.

\subsection{Pilot Study}

Pilot study were conducted on $10 \%$ of the sample size to test the applicability of the tools and the necessary modifications were made. Nine nurse managers who were involved in the pilot study were excluded from the research sample to ensure validity of the results.

\subsection{Research Process}

The research process started with obtaining ethical approval from each hospital. Aim and benefits were explained to participants by the researcher. Data collection required 8 months of work. Questionnaire distribution took place between November 2014 - April 2015, each Sunday and Wednesday weekly until completion of data. Questionnaires were handed to nurse managers by the researcher according to their free time (break time). The aim of the study was included in the questionnaire sheet and participants took 30-60 minutes to answer the questions. The questions were clear to the participants and did not require further explanation or clarification.

\subsection{Ethical Consideration}

The study has no potential or real harm on the participants'. The study benefits the managers, providing them with new information regarding delegation. The researcher respected the autonomy of the participants, who choose to withdraw from the study up until data collection stage finalized. Researcher informed mangers about the study. The aim of the study was explained to administrative 
personnel in each hospital, obtaining their approval to carry out the study with nurse managers. The aim of the study also were made clear to each nurse manger to familiarize them with the importance of participation. The researcher assured the participants of the confidentiality regarding information use for the purpose of the study only. KAUH ethical approval reference number is (159-14). Ethical approval Reference number for King Fahd General Hospital, Almsaeidih Maternity and Children's Hospital and King Abdulaziz Hospital Al Mahjar are (H-02-J-002). Ethical approval Reference number for King Faisal Specialist Hospital and Research Center is (RC-J/02/36).

\subsection{Data Analysis}

The data were analyzed by using the SPSS 16 computer software statistical package Chi-square, T-independent test and ANOVA. Descriptive statistics were used to analyze demographic data using percentages, frequencies, means and standard deviations.

\section{Results}

The findings revealed that the studied sample consisted of $10 \%$ males and $90 \%$ females. $(77.8 \%$ ) of the nurse mangers were married. Less than half $(43.3 \%)$ had no children. Slightly over two thirds of the studied sample (71.1\%) was aged 30-49 years. Just over half $(51.1 \%)$ of the nurse managers had a Bachelor degree and $60 \%$ had less than 5 years' experience. Regarding the skill mix, one-third (34\%) of the nurse managers were registered nurses. Approximately $65 \%$ had completed a leadership course and $73.3 \%$ had no managerial certificate. As regard $(55.6 \%)$ of the studied sample did not have an assistant nurse manager.

Table 1. Overall and priority of the statements of attitude to delegation as perceived by studied sample $(n=90)$.

\begin{tabular}{|c|c|c|c|c|c|c|c|c|}
\hline \multirow{2}{*}{ Statements } & \multicolumn{2}{|c|}{ Disagree } & \multicolumn{2}{|c|}{ Unsure } & \multicolumn{2}{|c|}{ Agree } & \multirow{2}{*}{$\begin{array}{l}\text { Weighted } \\
\text { Mean }\end{array}$} & \multirow{2}{*}{$\begin{array}{l}\text { Std. } \\
\text { Deviation }\end{array}$} \\
\hline & $\mathbf{F}$ & $\%$ & $\mathbf{f}$ & $\%$ & f & $\%$ & & \\
\hline $\begin{array}{l}\text { "(1)" I would delegate more, but the jobs I delegate never seem to get done the } \\
\text { way I want them to be done }\end{array}$ & 39 & 43.3 & 4 & 4.4 & 47 & 52.2 & 2.09 & 0.98 \\
\hline "(2)" I don’t feel I have time to delegate properly. & 60 & 66.7 & 4 & 4.4 & 26 & 28.9 & 1.62 & 0.91 \\
\hline "(3)" When I give clear instructions and the job is not done right, I get upset. & 26 & 28.9 & 6 & 6.7 & 58 & 64.4 & 2.36 & 0.90 \\
\hline $\begin{array}{l}\text { "(4)" I feel staff lack the commitment that I have, so any job I delegate will not } \\
\text { get done as well as I would do it. }\end{array}$ & 46 & 51.1 & 5 & 5.6 & 39 & 43.3 & 1.92 & 0.97 \\
\hline $\begin{array}{l}\text { "(5)" I would delegate more, but if the individual I delegate the task to does an } \\
\text { incompetent job, I will be severely criticized. }\end{array}$ & 48 & 53.3 & 7 & 7.8 & 35 & 38.9 & 1.86 & 0.95 \\
\hline $\begin{array}{l}\text { "(6)" When I delegate a job, I often find that the outcome is such that I end up } \\
\text { redoing the job myself. }\end{array}$ & 47 & 52.2 & 6 & 6.7 & 37 & 41.1 & 1.89 & 0.97 \\
\hline "(7)" I have not really found that delegation saves any time. & 56 & 62.2 & 15 & 16.7 & 19 & 21.1 & 1.59 & 0.82 \\
\hline $\begin{array}{l}\text { "(8)" I cannot delegate as much as I would like to because my subordinates lack } \\
\text { the necessary experience. }\end{array}$ & 50 & 55.6 & 9 & 10.0 & 31 & 34.4 & 1.79 & 0.93 \\
\hline "(9)" I would delegate more but I am pretty much a perfectionist. & 47 & 52.2 & 17 & 18.9 & 26 & 28.9 & 1.77 & 0.87 \\
\hline $\begin{array}{l}\text { "(10)" I can give subordinates the routine tasks, but I feel I must keep the non- } \\
\text { routine tasks myself. }\end{array}$ & 36 & 40.0 & 9 & 10.0 & 45 & 50.0 & 2.10 & 0.95 \\
\hline "(11)" I would delegate more if I were more confident in delegating. & 34 & 37.8 & 11 & 12.2 & 45 & 50.0 & 2.12 & 0.93 \\
\hline
\end{tabular}

\subsection{Nurse Mangers Attitudes to Delegation}

The overall responses and priority of the statements of studied sample attitude to delegation are presented in table 1. The results for most of the statements, and the whole factor, are unsure. This means nurse managers are unsure about their attitudes to delegation. Two-thirds of the sample (66.7\%) disagreed with the statement, "I do not feel I have time to delegate properly". About one-third (37.8\%) disagreed with the statement, "I would delegate more if I were more confident in delegating", while (64.4\%) agreed with the statement, "when I give clear instruction and the job is not done right I get upset", as opposed to the minority (21.1\%) who answered "I have not really found that delegation saves any time".

Table 2. The overall responses and priority of the statements from (1 to12) of competency to delegation as studied sample perception ( $n=90)$.

\begin{tabular}{|c|c|c|c|c|c|c|c|c|}
\hline \multirow{2}{*}{ Statements } & \multicolumn{2}{|c|}{ Never } & \multicolumn{2}{|c|}{ Sometimes } & \multicolumn{2}{|c|}{ Always } & \multirow{2}{*}{$\begin{array}{l}\text { Weighted } \\
\text { Mean }\end{array}$} & \multirow{2}{*}{$\begin{array}{l}\text { Std. } \\
\text { Deviation }\end{array}$} \\
\hline & f & $\%$ & f & $\%$ & f & $\%$ & & \\
\hline "(1)" Do you take account of staff's individual skills prior to delegation? & 2 & 2.2 & 17 & 18.9 & 71 & 78.9 & 2.77 & 0.48 \\
\hline "(2)" Do you give staff feedback following delegation (e.g. praise)? & 1 & 1.1 & 7 & 7.8 & 82 & 91.1 & 2.90 & 0.34 \\
\hline "(3)" Do you seek feedback from staff on whether you have explained the task sufficiently? & 0 & 0.0 & 13 & 14.4 & 77 & 85.6 & 2.86 & 0.35 \\
\hline "(4)" Do you seek feedback from staff to improve your delegation skills? & 7 & 7.8 & 16 & 17.8 & 67 & 74.4 & 2.67 & 0.62 \\
\hline "(5)" Do you find you spend a lot of time on jobs others could do? & 13 & 14.4 & 37 & 41.1 & 40 & 44.4 & 2.30 & 0.71 \\
\hline "(6)" Do you think you give up power or lose respect because of delegation? & 53 & 58.9 & 21 & 23.3 & 16 & 17.8 & 1.59 & 0.78 \\
\hline "(7)" Are you concerned that staff may find you lazy for delegating tasks? & 61 & 67.8 & 21 & 23.3 & 8 & 8.9 & 1.41 & 0.65 \\
\hline "(8)" In delegation, do you make clear who is to do the task? & 1 & 1.1 & 9 & 10.0 & 80 & 88.9 & 2.88 & 0.36 \\
\hline "(9)" In delegation, do you make it clear when to do the task? & 2 & 2.2 & 3 & 3.3 & 85 & 94.4 & 2.92 & 0.34 \\
\hline "(10)" In delegation, do you make it clear where to do the task? & 2 & 2.2 & 5 & 5.6 & 83 & 92.2 & 2.90 & 0.37 \\
\hline "(11)" In delegation, do you make clear why to do the task? & 1 & 1.1 & 7 & 7.8 & 82 & 91.1 & 2.90 & 0.34 \\
\hline "(12)" In delegation, do you make it clear how to do the task? & 1 & 1.1 & 6 & 6.7 & 83 & 92.2 & 2.91 & 0.32 \\
\hline
\end{tabular}


Table 3. The overall responses and priority of the statements from (13 to20) of competency to delegation as studied sample perception ( $n=90)$.

\begin{tabular}{|c|c|c|c|c|c|c|c|c|}
\hline \multirow{2}{*}{ Statements } & \multicolumn{2}{|c|}{ Disagree } & \multicolumn{2}{|c|}{ Unsure } & \multicolumn{2}{|c|}{ Agree } & \multirow{2}{*}{$\begin{array}{l}\text { Weighted } \\
\text { Mean }\end{array}$} & \multirow{2}{*}{$\begin{array}{l}\text { Std. } \\
\text { Deviation }\end{array}$} \\
\hline & f & $\%$ & f & $\%$ & f & $\%$ & & \\
\hline $\begin{array}{l}\text { "(13)" Nursing staff skills \& knowledge could be better utilized with more effective } \\
\text { delegation. }\end{array}$ & 5 & 5.6 & 3 & 3.3 & 82 & 91.1 & 2.86 & 0.49 \\
\hline "(14)" Rules regarding delegation have made me delegate more than before. & 12 & 13.3 & 17 & 18.9 & 61 & 67.8 & 2.54 & 0.72 \\
\hline "(15)" My responsibilities regarding the nursing activities hinder effective delegation. & 25 & 27.8 & 10 & 11.1 & 55 & 61.1 & 2.33 & 0.89 \\
\hline "(16)" I have received sufficient preparation to delegate through my education or at work. & 8 & 8.9 & 14 & 15.6 & 68 & 75.6 & 2.67 & 0.64 \\
\hline $\begin{array}{l}\text { "(17)" Effective delegation improves staff development and satisfaction, which results in } \\
\text { better patient care and patient satisfaction. }\end{array}$ & 1 & 1.1 & 3 & 3.3 & 86 & 95.6 & 2.94 & 0.27 \\
\hline "(18)" I find it clear which tasks can be delegated to nursing staff. & 0 & 0.0 & 1 & 1.1 & 89 & 98.9 & 2.99 & 0.11 \\
\hline "(19)" I have sufficient skills to face staff 's negative reaction when delegating tasks. & 2 & 2.2 & 7 & 7.8 & 81 & 90.0 & 2.88 & 0.39 \\
\hline "(20)" I am familiar with my legal responsibilities when delegating to others. & 0 & 0.0 & 0 & 0.0 & 90 & 100.0 & 3.00 & 0.00 \\
\hline
\end{tabular}

\subsection{Nurse Managers Competency to Delegate}

Table 2 described the overall responses of the statements from 1 to 12 were 'always', Two-thirds $(67.8 \%)$ of the studied sample responded with 'never' to the statement; "Are you concerned that the staff finds you lazy for delegating tasks", while less than half $(41.1 \%)$ of the studied sample answered 'sometimes' to the statement; "Do you find you spend a lot of time on jobs others could do?" Furthermore, the majority of the studied sample responded 'always' to the following statements; "Do you give staff feedback following delegation (e.g. praise)?", "In delegation, do you make it clear why to do the task?", "In delegation, do you make it clear where to do the task?", "In delegation, do you make it clear how to do the task?", and "In delegation, do you make it clear when to do the task?", 94.4\%, 92.2\%, 92.2\%, 91.1\% and $91.1 \%$ respectively respondents answered 'always' to the afore mentioned statements.

Table 3 represented the overall responses of the statements from 13 up to 20 were 'agree'. However, (27.8\%) of the sample disagreed with the statement: "My responsibilities regarding nursing activities hinder effective delegation", and $18.9 \%$ were 'unsure' about the following statement; "Rules regarding delegation have made me delegate more than before". All nurse managers 'agreed' with the statement, "I am familiar with my legal responsibilities when delegating to others". Additionally, the majority of studied sample 'agreed' with the following statements; "I find it clear which tasks can be delegated to nursing staff"(98.9\%), "Effective delegation improves staff development and satisfaction, which results in better patient care and patient satisfaction" (95.6\%), "Nursing staff skills and knowledge could be better utilized with more effective delegation" (91.1\%), and "I have sufficient skills to face staff's negative reaction when delegating tasks"(90\%).

Table 4. Exhibited mean score difference between opinion and attitude of studied sample regarding demographic variables ( $n=90$ ).

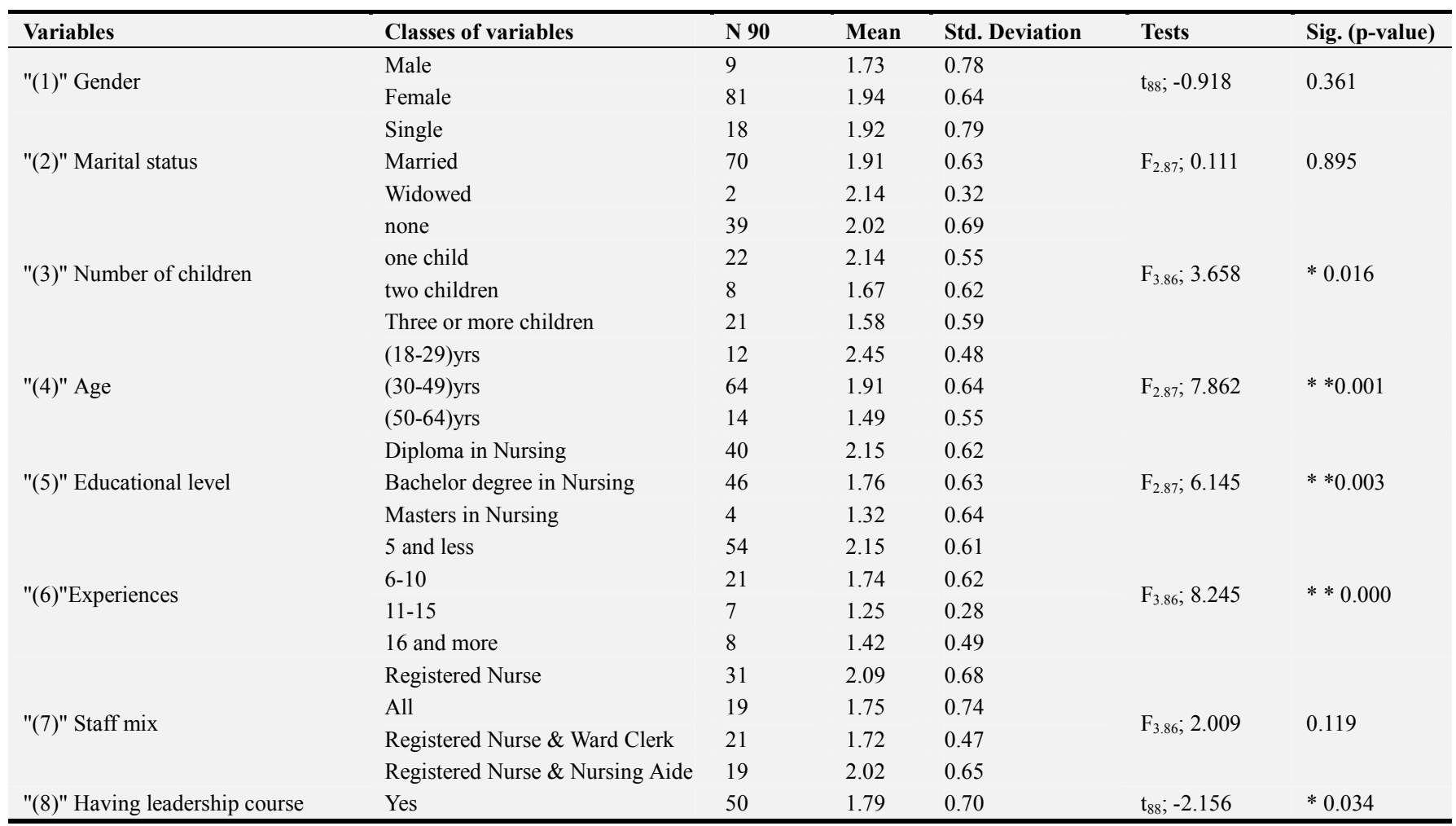




\begin{tabular}{lllllll}
\hline Variables & Classes of variables & N 90 & Mean & Std. Deviation & Tests & Sig. (p-value) \\
\hline & No & 40 & 2.08 & 0.57 & & \\
"(9)" Having Managerial certificate & Yes & 24 & 24 & 1.75 & \multirow{2}{*}{ t } \\
& No & 66 & 66 & 1.98 & & \\
& None & 50 & 1.93 & 0.64 & \multirow{2}{*}{ F $_{3.86} ; 0.011$} & 0.153 \\
"(10)"Having Assistants & One & 27 & 1.90 & 0.69 & \\
& More than one & 13 & 1.92 & 0.69 & & \\
\hline
\end{tabular}

"t 885 is the value of the t- statistic at (88) degree of freedom

Table 4 displayed the mean score difference of opinions and attitudes of the studied sample regarding demographic variables. These results indicate that there is relationship between the number of children, age, educational level, experience and having completed a leadership training course $(p \leq 0.05)$. There is no correlation with gender, marital status, staff mix, having a managerial certificate or having an assistant $(p \geq 0.05)$.

Table 5. Presented mean score difference between opinion and competency of the studied sample regarding demographic variables ( $n=90)$.

\begin{tabular}{|c|c|c|c|c|c|c|}
\hline Variables & Classes of variables & N 90 & Mean & Std. Deviation & tests & Sig. (p-value) \\
\hline \multirow{2}{*}{ "(1)" Gender } & Male & 9 & 2.61 & 0.22 & \multirow{2}{*}{$\mathrm{t}_{88} ;-0.954$} & \multirow{2}{*}{0.343} \\
\hline & Female & 81 & 2.67 & 0.18 & & \\
\hline \multirow{3}{*}{ "(2)" Marital status } & Single & 18 & 2.63 & 0.18 & \multirow{3}{*}{$\mathrm{F}_{2.87} ; 0.672$} & \multirow{3}{*}{0.513} \\
\hline & Married & 70 & 2.67 & 0.19 & & \\
\hline & Widowed & 2 & 2.55 & 0.07 & & \\
\hline \multirow{3}{*}{ "(3)" Number of children } & none & 39 & 2.66 & 0.15 & \multirow{3}{*}{$\mathrm{F}_{3.86} ; 0.259$} & \multirow{3}{*}{0.855} \\
\hline & two children & 8 & 2.63 & 0.14 & & \\
\hline & three or more children & 21 & 2.65 & 0.22 & & \\
\hline \multirow{3}{*}{ "(4)" Age in years } & $(18-29)$ & 12 & 2.70 & 0.15 & \multirow{3}{*}{$\mathrm{F}_{2.87} ; 2.456$} & \multirow{3}{*}{0.092} \\
\hline & $(30-49)$ & 64 & 2.68 & 0.18 & & \\
\hline & $(50-64)$ & 14 & 2.56 & 0.18 & & \\
\hline \multirow[b]{2}{*}{ "(5)" Educational level } & Diploma in Nursing & 40 & 2.70 & 0.16 & \multirow[b]{2}{*}{$\mathrm{F}_{2.87} ; 2.056$} & \multirow[b]{2}{*}{0.134} \\
\hline & Bachelor degree in Nursing & 46 & 2.63 & 0.20 & & \\
\hline \multirow{4}{*}{ "(6)" Experiences } & 5 and less & 54 & 2.71 & 0.17 & \multirow{4}{*}{$\mathrm{F}_{3.86} ; 5.202$} & \multirow{4}{*}{$* * 0.002$} \\
\hline & $6-10$ & 21 & 2.63 & 0.18 & & \\
\hline & $11-15$ & 7 & 2.59 & 0.13 & & \\
\hline & 16 and more & 8 & 2.48 & 0.17 & & \\
\hline \multirow{4}{*}{ "(7)" Staff mix } & Registered Nurse & 31 & 2.74 & 0.14 & \multirow{4}{*}{$F_{3.86} ; 5.164$} & \multirow{4}{*}{$* * 0.002$} \\
\hline & All & 19 & 2.57 & 0.19 & & \\
\hline & Registered Nurse \&Ward Clerk & 21 & 2.60 & 0.19 & & \\
\hline & Registered Nurse \& Nursing Aide & 19 & 2.69 & 0.17 & & \\
\hline \multirow{2}{*}{ "(8)" Having completed a leadership course } & Yes & 50 & 2.61 & 0.18 & \multirow{2}{*}{$\mathrm{t}_{88} ;-2.944$} & \multirow{2}{*}{$* * 0.004$} \\
\hline & No & 40 & 2.72 & 0.17 & & \\
\hline \multirow{2}{*}{ "(9)" Having Managerial certificate } & Yes & 24 & 24 & 2.61 & \multirow{2}{*}{$\mathrm{t}_{88} ;-1.655$} & \multirow{2}{*}{0.102} \\
\hline & No & 66 & 66 & 2.68 & & \\
\hline "(10)" Having Assistants & None & 50 & 2.65 & 0.20 & $\mathrm{~F}_{3.86} ; 0.485$ & 0.618 \\
\hline
\end{tabular}

*: Statistically significant at $\mathrm{p} \leq 0.05$

Table 5 displayed the mean score difference between nurse mangers opinions and competency regarding demographic variables. The results indicated that there is a relationship between experience, staff mix and having completed a leadership course $(p \leq 0.05)$, whilst there is no relationship with the gender, marital status, number of children, age, educational level, having a managerial certificate or having an assistant $(p \geq 0.05)$.

Table 6. Correlation between nurse mangers attitude and competency regarding delegation $(n=90)$.

\begin{tabular}{lll}
\hline Factors & & 1- Nurse manger attitude to delegation. \\
\hline \multirow{2}{*}{ 2- Nurse manger competency to delegate. } & Pearson correlation & $0.599 * *$ \\
& Sig & $0.000 * *$ \\
\hline
\end{tabular}

\footnotetext{
${ }^{* *}$ Correlation is significant at the 0.01 level (2-tailed)
} 
Table 6 shown that there is a highly significant correlation between the attitude and competency where Pearson correlation coefficient is $0.000^{* *}$.

\section{Discussion}

\subsection{Nurse Mangers Attitude}

In relation to nurse manager's attitudes, the results for most of the statements and the whole factor are unsure. This finding is at odds with the earlier findings of Kaernested \&Bragadottir (2012), where participants reported positive attitudes regarding delegation [16]. Two-third of the studied sample disagreed with the statement that they did not feel they have time to delegate properly. The findings of the present study are supported by Marquis \& Huston (2009) who suggested that nurse managers at all levels should delegate tasks to save time [18]. One-third of studied sampled disagreed that they would delegate more if they were more confident in delegating. This result was incongruent to the findings of Bystedt et al. (2011), in which participants stated that they felt insecure and lacked confidence when delegating because of the potential risk for negative outcomes [7]. Saccomano \& Pontozipp (2010) found that diploma nurses were less confident about delegating to nursing aides in comparison to nurses who held a Bachelor degrees and who had a higher level of confidence in delegation [26]. Bittner \& Gravlin (2009) found that new graduate nurses spoke about 'role uncertainty' and how their lack of confidence prevented them from delegating [5]. Whereas the majority of nurse managers agreed that they would be upset if they gave a subordinate clear instructions only to find that the job was not done correctly Potter et al. (2010) support this finding, their study participants indicating that they got mad when delegatees failed to follow their exact instructions [23]. According to Anthony and Vidal (2010) [2], continuous update of any potential adverse outcome is the key to overcoming this issue. Successful delegation requires cooperation, mutual respect, trust, feedback and communication (Bittner \&Gravlin, 2009; Cipriano, 2010) [5]-[8]. Additionally, minority of the studied sample agreed that delegation did not save time. These findings is different from Bergman and Shubert (2013), who highlighted the importance of time management and how it delegation saves time [3].

\subsection{Nurse Mangers Competency}

With regard to nurse managers competency, the overall response to most of the statements from 1-12 were 'always', while the overall response to statements 13-20 was 'agree'. This result conflicts with those of Kaernested \&Bragadottir (2012), who found that participants were not competent to delegate, while this study found that participants were competent and ready to delegate [16]. Two-third of studied sample responded that they were never concerned that staff found them lazy for delegating tasks. Marquis \& Huston
(2012) support this finding, especially that one of the common delegation errors is under-delegation, which occurs because some managers are obsessive about control or because they are afraid that they will be viewed as unable to perform their role [19]. Less than half of the sample answered that sometimes they spent a lot of time on jobs others could do. A similar result was recorded in studies conducted by Weydt (2010), Kaernested \& Bragadottir (2012), in which participants stated that they spent a lot of time on jobs others could do [31]-[16]. Almost all nurse managers responded 'always' for giving feedback to staff following delegation and making clear who is to do the delegation, reasons for performing the task, where to do the task, how to do the task, who is to do the task and when to do it. This finding is supported by Standing \& Anthony (2008) thier research participants stated that they viewed communication as a basic element of successful delegation [27]. This result is further supported by Curtis \& Honor (2004), Sullivan \& Decker (2009), stressing the importance of providing feedback, which includes guidance and comments on how the job was done [9] [28]. The concept of feedback was supported by Anthony and Vidal (2010), who illustrated the importance of providing feedback to delegators in terms of continuous updates about information that might affect the quality of their work [2]. Participants in the study conducted by Bittner \& Gravlin (2009) reported that they found that delegatees frequently did not understand the instructions given to them, largely due to language barriers [5]. However, a minority of nurse managers disagreed that their responsibilities regarding nursing activities, hindered effective delegation. Tucker \& Spear (2006) disagree with this finding, concluding that delegators spend $10-25 \%$ of their time supervising delegates [30]. Kelly (2010) approved this finding staying that delegators carry the responsibility of planning, monitoring and following up and it does not affect delegation [17].

Minority of the nurse managers were unsure whether rules regarding delegation making them delegate more or not. This finding was at odds with the earlier findings of Dimond (2008), who found that rules made delegation easier, because such rules were born of policies, procedures, leadership functions, job descriptions and guidelines on how to delegate [10].

All nurse managers agreed that they were familiar with their legal responsibilities when delegating to others, and this result was supported by the National Council of State Boards of Nursing (2012), who published a detailed delegation process, identifying each situation and whether delegation should happen or not. Such guidelines help delegators feel secure while delegating [21]. However, the majority of participants agreed that they found it clear enough what tasks they could delegate. In the study by Josephsen (2013), participants described the use of pre-made instructional policies as useful in delegating, especially in respect of legal issues [15]. Gillen \& Graffin (2010) agreed with this result indicating that clear policies make delegation practice much 
easier. Professional guidelines can assist the delegator in building a basic legal foundation for delegation. Additionally, they agreed that effective delegation improved staff development and satisfaction, thus resulting in better patient care and patient satisfaction [11]. Sullivan \& Decker (2009) confirmed this finding, reporting that delegation taught delegatees new skills. Delegation also builds self-esteem, trust, confidence, improves job satisfaction, increases motivation and morale, brings a sense of pride, increases awareness and improves cooperation and team work [28]. Gordon \& Barry (2009) reported that delegation gave participants in their study a sense of empowerment and knowledge; they felt they had the power to make choices and decisions, expressed a sense of trust and support, and agreed that delegation made a difference [12]. Additionally, the majority of participants agreed that nursing staff skills and knowledge could be better utilized with effective delegation. Weydt (2010) granted this finding, suggesting that a lack of delegation could jeopardize quality and result in resources mismanagement [31]. Moreover, they agreed that they have the necessary skills to face staff negative reaction. Marquis \&Huston (2012) proposed that the delegator should confront delegatees about the reasons behind their resistance and ask why the task was not done correctly [19].

\subsection{Nurse Mangers Attitude and Demographics Data Relationship}

In respect of nurse managers attitudes/opinions and their demographic characteristics, the findings revealed that there was a significant relationship between several demographic characteristics, including the number of children, age, educational level, experience and having completed a leadership course $(p<0.05)$. There was no significant relationship between gender, marital status, staff mix, having a managerial certificate and having an assistant $(p>0.05)$. Kaernested \& Bragadottir (2012) similarly reported a relationship between age and delegation, that older nurses were more comfortable with delegation and less concerned that that they would be called 'lazy' [16]. This result is further supported by Standing\&Anthony (2008), Berkow et al. (2008), and Potter et al. (2010), who confirmed that there is a relationship between delegation skills and experience among nurse mangers, suggesting that years of experience results in one improving and growing with practice over time [27]-[4]-[23]. Ruff (2011) and Gravlin \& Bittner (2010) confirm a relationship between delegation and education, observing that nursing education is key to ensuring appropriate delegation [25]-[13]. Conversely, Saccomano \& Pinto (2011) found that education had no relationship to delegation and that diploma nurses were better prepared to delegate than bachelor degree nurses because they had more years of exposure to real situation of delegation [26]. White et al. (2011) contradicted this finding, reporting that certification had a significant relationship with delegation and those participants who held certification had more knowledge about delegation [32].

\subsection{Nurse Manger Competency and Demographics Data Relationship}

In terms of nurse managers opinions regarding competency and demographic characteristics, a significant relationship was found to exist between experience, skill mix and having completed a leadership course $(p<0.05)$. No significant relationship was observed with gender, number of children, marital status, age, educational level, having a managerial certificate or having an assistant $(p>0.05)$. Saccomano \& Pontozipp (2011) assured that experience is related to competency in delegation [26]. Weydt (2010) argues that delegation skills can be taught by way of simulation and practice, as simulation can include the teaching of complex professional skills needed for delegation, such as management, leadership, communication and partnership [31]. With respect to leadership courses, Josephsen (2013) reported that $81-100 \%$ of participants stated that they acquired the concept of delegation through online courses, which attests to the relationship between leadership courses and delegation [15].

It can therefore be concluded that attitudes and competency are decidedly related to each other, and this finding supports the results of Kaernested \& Bragadottir (2012) who also concluded that attitudes and competency were the basis of delegation and were associated with age, experience, communication and training in delegation [16].

\section{Conclusion}

The findings of this study were that participants are unsure about their attitude to delegation, but the majority agreed that they would be annoyed if the job is not done correctly or if instructions were not followed carefully. Participants did not acquire all the facts and principles of delegation. Regarding competency in delegation, participants agreed that they understood all the aspects of legality and the importance of providing clear instruction, which mainly involves communication and they believed that they have the necessary knowledge. It was also found that confidence in delegation was linked to experience, education and leadership skills.

\section{Recommendation}

1. Nurse managers should facilitate the delegation process through developing clear guidelines as well as creating an environment that supports delegation, resolution of conflict and encourages teamwork.

2. Nursing research should focus on nursing professionals' accountability; research will help nurses to understand the real definition of accountability and its standards.

3. Nurses need to be taught about delegation, as increased knowledge can guarantee better delegation outcomes.

4. Nurse leaders must work on creating a culture of safety and honest assessment to improve the practice of delegation. 


\section{References}

[1] Al Aameri, A. (2003). Source of job stress for nurses in public hospitals. Saudi Medical Journal, 24 (11), 1183-1187.

[2] Anthony, M. K., \& Vidal, K. (2010). Mindful communication: A novel approach to improving delegation and increasing patient safety. Online Journal of Issues in Nursing, 15 (2), Manuscript 2.

[3] Bergman, C., \& Shubert, L. (2013). Interactive strategies: Time management, prioritization and delegation. Nurse Educator, $38 \quad$ (4), 137-138. doi:10.1097/nne.0b013e318296dcb6.

[4] Berkow, S., Virkstis, K., Stewart, J., \& Conway, L. (2008). Assessing new graduate nurse performance. The Journal of Nursing Administration, $38 \quad$ (11), 468-474. doi:10.1097/01.nne.0000343405.90362.15.

[5] Bittner, N., \& Gravlin, G. (2009). Critical thinking, delegation, and missed care in nursing practice. Journal of Nursing Administration, 39 (4), 142-146.

[6] Brewer, C. Kovner, C. Greene, W. Tukov-Shuser, M. \&Djukic, M. (2011). Predictors of actual turnover in a national sample of newly licensed registered nurses employed in hospitals. Journal of Advanced Nursing, 68 (3), 521-538.

[7] Bystedt, M., Eriksson, M., \& Wilde-Larsson, B. (2011). Delegation within municipal health care. Journal of Nursing Management, 19 (4), 534-541.

[8] Cipriano, P. (2010). Overview and summary: Delegation dilemma: Standards and skills for practice. Online Journal of Issues in Nursing, 15 (2), 1-3. doi:10.3912/OJIN.Vol15No02ManOS

[9] Curtis, E., \& Nicholl, H. (2004). Delegation: A key function of nursing. Nursing Management, 11 (4), 26-31.

[10] Dimond, B. (2008). Legal aspects of nursing (5th ed.). Harlow, England: Pearson Education.

[11] Gillen, P., \& Graffin, S. (2010). Nursing delegation in the United Kingdom. Online Journal of Issues in Nursing, 15 (6), $1-19$.

[12] Gordon, S., \& Barry, C. (2009). Delegation guided by school nursing values: Comprehensive knowledge trust and empowerment. The Journal of School of Nursing, 25 (5), 352360. doi:10.1177/1059840509337724.

[13] Gravlin, G., \& Bittner, N. (2010). Nurses and nursing assistants report of missed care and delegation. Journal of Nursing Administration, 40 (7), 329-335.

[14] Huston, C. (2006). Professional issues in nursing. Philadelphia, PA: Lippincott Williams \& Wilkins.

[15] Josephsen, J. (2013). Teaching nursing delegation: An online case study. Teaching and Learning in Nursing, 8 (3), 83-87.

[16] Kærnested, B., \& Bragadóttir, H. (2012). Delegation of registered nurses revisited: Attitudes towards delegation and preparedness to delegate effectively. Nordic Journal of Nursing Research, 32 (1), 10-15.

[17] Kelly, P. (2010). Essential of nursing leadership and management (2nd ed.). Clifton Park, NY: Delmar Cengage Learning.

[18] Marquis, B., \& Huston, C. (2009). Leadership roles and management functions in nursing (6th ed.). Philadelphia, PA: Lippincott Williams \& Wilkins.

[19] Marquis, B., \& Huston, C. (2012). Leadership roles and management functions in nursing (7th ed.). Philadelphia, PA: Lippincott Williams \& Wilkins.

[20] Mueller, C., \& Vogelsmeier, A. (2013). Effective delegation: Understanding responsibility, authority and accountability. Journal of Nursing Regulation, 4 (3), 20-27.

[21] National Council of State Boards of Nursing (2012). Transition to practice is a trademark. Retrieved from https://www.ncsbn.org/323.htm.

[22] Poteet, G. (1984). Delegation Strategies A Must for the Nurse Executive. Journal of Nursing Administration, 14 (9), 18-21.

[23] Potter, P., Deshields, T., \& Kuhrik, M. (2010). Delegation practices between registered nurses and nursing assistive personnel. Journal of Nursing Management, 18 (2), 157-165.

[24] Resha, C. (2010). Delegation in the school setting: Is it a safe practice?. Online Journal of Issues in Nursing, 15 (2).

[25] Ruff, V. (2011). Delegation skills: Essential to the contemporary nurse (Masters dissertation). St. Catherine University. Retrieved from http://sophia.stkate.edu/cgi/viewcontent.cgi?article=1020\&co ntext=ma_nursing.

[26] Saccomano, S., \& Pontozipp, G. (2011). Registered nurse leadership style and confidence in delegation. Journal of Nursing Management, 19 (4), 522-533.

[27] Standing, T., \& Anthony, M. (2008). Delegation: What it means to acute care nurses. Applied Nursing Research, 21 (1), 8-14. doi:10.1016/j.apnr.2006.08.010.

[28] Sullivan, E. \& Decker, P. (2009). Effective leadership and management in nursing (7th ed.). Upper Saddle River, NJ: Pearson Prentice Hall.

[29] Tómasdóttir, I \& Geirsdóttir (1998). Úthlutun verkefna $i$ hjúkrun.

[30] Tucker, A. L., \& Spear, S. J. (2006). Operational failures and interruptions in hospital nursing. Health Services Research, 41 (3p1), 643-662.

[31] Weydt, A. (2010). Developing delegation skills. Online Journal of Issues in Nursing, 15 (2).

[32] White, M., Gutierrez, A., Davis, K., Olson, R., \& Mclaughlin, C. (2011). Delegation knowledge and practice among rehabilitation nurses. Rehabilitation Nursing, 36 (1), 16-24. 